\title{
Article
}

\section{Length of labour in mothers and their daughters: A matched cohort study}

\author{
Ebrahimoff, Mindy, Many, Ariel, Downe, Soo, Tishkovskaya, \\ Svetlana and Moran, Victoria Louise \\ Available at http://clok.uclan.ac.uk/31232/ \\ Ebrahimoff, Mindy, Many, Ariel, Downe, Soo ORCID: 0000-0003-2848-2550, \\ Tishkovskaya, Svetlana ORCID: 0000-0003-3087-6380 and Moran, Victoria \\ Louise ORCID: 0000-0003-3165-4448 (2020) Length of labour in mothers and \\ their daughters: A matched cohort study. European Journal of Obstetrics \& \\ Gynecology and Reproductive Biology, 245 . pp. 77-83. ISSN 0301-2115
}

It is advisable to refer to the publisher's version if you intend to cite from the work. http://dx.doi.org/10.1016/j.ejogrb.2019.12.007

For more information about UCLan's research in this area go to http://www.uclan.ac.uk/researchgroups/ and search for < name of research Group>.

For information about Research generally at UCLan please go to http://www.uclan.ac.uk/research/

All outputs in CLoK are protected by Intellectual Property Rights law, including Copyright law. Copyright, IPR and Moral Rights for the works on this site are retained by the individual authors and/or other copyright owners. Terms and conditions for use of this material are defined in the policies page.

\section{CLoK}

Central Lancashire online Knowledge www.clok.uclan.ac.uk

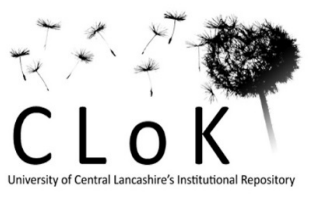


Full length article

\title{
Length of labour in mothers and their daughters: A matched cohort study
}

\author{
Mindy Ebrahimoff ${ }^{\text {ab }}$ Ariel Many ${ }^{\mathrm{b}}$ Soo Downe ${ }^{\mathrm{a}}$ Svetlana Tishkovskaya ${ }^{\mathrm{a}}$ Victoria Hall-Moran ${ }^{\mathrm{a}}$ \\ ${ }^{a}$ University of Central Lancashire, Preston, United Kingdom

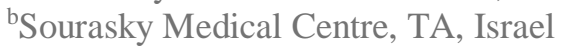

\section{Objective}

Physiological length of labour is highly variable and population norms have low sensitivity and specificity for individuals. The birth history of mothers may provide a basis for personalized assessment of labour progress in their nulliparous daughters. This study was designed to investigate the relationship between length of labour in nulliparous daughters and in their mother's first birth, as a basis for constructing individualised labour prediction models in future.

\section{Study design}

A mother-daughter matched cohort study was conducted in two Israeli maternity hospitals. Recruitment took place between September 2014 and June 2015 via antenatal clinics. Inclusion criteria were nulliparous daughters with singleton pregnancies at $\geq 32$ weeks' gestation and mothers of included daughters who had a first birth in hospital prior to 1997. Data were collected prospectively for daughters by questionnaire and from electronic hospital records, and through retrospective recall questionnaires for mothers. Mother-daughter length of labour data were analysed using parametric and nonparametric tests and logistic regression. Length of labour was categorized as $\leq 10 \mathrm{~h}$ and $>10 \mathrm{~h}$. Other factors influencing daughters' length of labour were also examined.

\section{Results}

Data from 323 mother-daughter pairs were analysed. Univariate logistic regression analysis showed that daughters of mothers who were in active labour for more than $10 \mathrm{~h}$ showed increased likelihood of having a longer labour [OR1.91 (95 \% CI 1.19, 3.05, $\mathrm{P}=0.007)$ ]. Controlling for infant gender increased the effect size [OR3.23 (95\% CI $1.55,6.74, \mathrm{P}=0.002)]$. Multivariable logistic regression indicated that mothers' length of 
labour [OR1.88 (95 \% CI 1.12, 3.17)] and daughters' age [OR1.08 (95 \% CI 1.02, 1.14)], weight gain in pregnancy [OR1.10 (95\% CI 1.04, 1.16)] and use of anesthesia, were statistically significant factors for daughters' length of labour, with sensitivity, specificity, and positive and negative predictive values of $74 \%, 56 \%, 66 \%$, and $64 \%$, respectively.

\section{Conclusions}

A strong positive association between mother and daughter lengths of labour was found. A model that includes length of labour in their mother's first birth might be useful for labour progress prediction for nulliparous women. Practitioners could inquire about maternal first birth patterns as an additional heuristic to guide practice and increase precision in the clinical management of nullipara women's labour and delivery.

\section{Keywords}

Mother; Daughter; Familial; Birth history; Nullipara

\section{Introduction}

There is increasing debate about safe limits for labour length. Average population labour curves do not reflect individual variability in labour progress [1,2]. Population norms may not be relevant for clinical decisions related to particular women in labour [3]. Moreover, overly conservative definitions of labour dystocia may be associated with rising caesarean section rates [4].

The concept of 'slow but normal labour' is beginning to appear in the literature [1]. In current clinical practice, however, such labours tend to be diagnosed as dystocic, and therefore as indicative of underlying pathology [5]. In addition, nulliparous women are more likely to be diagnosed with slow labour progress [5]. Women admitted to labour wards early in labour (cervical dilation $<4 \mathrm{~cm}$ ) have a two, [6], three [7] or four [8] times higher risk of delivery by caesarean than women admitted later in labour.

Known associations between mother-daughter reproductive outcomes include gestational age [9], birthweight [10,11], prolonged pregnancy [12,13], labour dystocia [14,15], 
assisted vaginal birth, and caesarean section $[16,17]$. However, there appear to be no reports of matched cohort studies comparing mother-daughter labour length.

This study investigated associations between length of labour in nulliparous women, and in their biological mother's first birth.

\section{Materials and methods}

In a matched cohort study design, nulliparous (index) women over 17 years of age, >32 weeks' gestation, who were able to give consent, and who were attending antenatal clinics in either of two Israeli hospitals between September 2014-June 2015, were recruited. Eligible women received questionnaires and participant information sheets for themselves and for their mothers. Recruitment depended on return of signed consent forms from both mother and daughter. Project approval was granted by the ethics committees of the Sourasky Medical Centre, ref:0039-14,12.06.2014; Ma'ayney Hayeshua Hospital, ref:72.14,30.07.2014; and University of Central Lancashire Research Ethics Committee, UK; ref:STEMH 255,09.09.2014.

Index women's questionnaires included name, national identity number (for tracking records), personal and demographic information, and due date. Mothers' questionnaires included personal and demographic information, general and obstetric health histories, and prenatal and perinatal information.

Daughters' birth data were collected retrospectively from the electronic hospital database and included: age at first period, height, education, marital status, weight-gain in pregnancy, signs of labour onset, analgesia, augmentation, labour length, age at first delivery, delivery outcome, fetal birthweight, gestational age, Apgar score and gender.

Length of labour was measured on a continuous scale for index women. For their mothers, a categorical scale was used, as follows:

1) $\leq 2 \mathrm{~h}$

2) $>2-6 h$ 
3) $>6-10 \mathrm{~h}$

4) $>10 \mathrm{~h}$, please state the number of hours:

Mothers were not asked to record labour length in hours and minutes because, though maternal recall of events around birth is known to be generally reliable, it is unlikely that women would remember precise details of length of labour. Our particular interest was in longer labours. The four time intervals were based on the findings of a systematic review on active labour duration rates among 7009 low-risk nulliparous women with spontaneous labour onset that reported a mean active labour duration of $6 \mathrm{~h} \pm S D 3.5 \mathrm{~h}$ [5]. We therefore used four-hour end points (categories 2 and 3), and accounted for short $(\leq 2 \mathrm{~h})$ and long $(>10 \mathrm{~h})$ labours. Completed mother-daughter questionnaires were returned by index women at ante-natal visits or via Freepost.

Following linkage of the mother-daughter data, questionnaire and birth record data were anonymized, numbered and assessed manually for errors. Missing data or ambiguous values were queried by telephone conversation. Women who had an elective caesarean section were included in the sample descriptive analysis but excluded from the modelling, as they did not labour. Clinical interventions that could impact on length of labour, such as induction/augmentation of labour, vacuum extraction/forceps delivery, or emergency caesarean section during labour were explored. Data were analysed with SPSS version 24.0. (Armonk, NY:IBM Corp.).

Sample size was estimated using the formula $n=10 * \mathrm{k} / \mathrm{p}[18]$ where $\mathrm{k}$ is the number of covariates and $\mathrm{p}$ is the smallest proportion of negative or positive cases in the population (short/long labour cases). This gave a sample size estimate of $n=311$ daughters with 14 factors and $\mathrm{p}$ taken as 0.45 (proportion of short labour cases in daughters). A sample size of 337 mother-daughter pairs was used to allow for exclusions in analysis for statistical modelling of which either participant of a pair had had an elective caesarean.

Mothers and daughters' length of labour was measured from onset of labour to time of birth. For mothers who laboured for more than $10 \mathrm{~h}$, indications for labour onset were verified by telephone conversation and calculated from when the participants reported strong, regular, painful contractions and/or hospital admission and vaginal examination 
showing a cervical dilation of at least 4-centimeters. Daughters' onset of labour was determined from documentation of a minimum of 4-centimeters cervical dilation in the clinical records following hospital admission, and if they were also experiencing regular uterine activity and intense painful contractions.

Descriptive statistics provided information on sample characteristics. Continuous variables were checked for normality of distribution including age at first period, height, weight-gain in pregnancy, age at first delivery, fetal birthweight, and gestational age. Paired $t$-test and Wilcoxon test were used to compare continuous variables. McNemar's test was used for binary variables, and marginal homogeneity test for categorical variables. Significance was defined as $p<0.05$. Daughters' length of labour was dichotomized $(\leq 10 \mathrm{~h} />10 \mathrm{~h})$ and analysed with logistic regression. Clinically, dichotomization of length of labour offers a risk classification into high versus low, which may assist in making treatment recommendations and in setting diagnostic criteria. Daughters dichotomized length of labour was explored using univariate regression with the following independent variables: mothers' length of labour (binary), fetal birthweight, and gestational age, and index woman's height, education, age, weight-gain, induction, augmentation, use of anesthesia, fetal birthweight, gestational age, type of birth, and gender of the baby. Any variable which reached 0.1 level of statistical significance in the univariate logistic regression was selected and used in a multivariable logistic regression model with standard method of variables entry in SPSS. Candidate predictors were systematically removed to find the best model fit. The Hosmer and Lemeshow [19] test was used as a goodness-of-fit test. The following combinations of potential interactions among daughters' variables were tested: fetal birthweight/induction, gestational age/augmentation, labour onset/delivery mode and fetal birthweight/gestational age but were not found statistically significant. Sensitivity and specificity were calculated for the model. Assumptions for the logistic regressions were checked. No multi-collinearity was found between predictor variables. Outliers were checked for their impact on the regression model and a receiver operating characteristic (ROC) curve was applied. No imputation was performed for missing data. 


\section{Results}

Of the 450 paired questionnaires distributed, 360 paired completed questionnaires were returned (response rate $80 \%$ ). Twenty-three (6\%) paired participants were excluded; 4 $\%(n=15)$ with incomplete questionnaires, and $2 \%(n=8)$ with multiple gestations.

Excluded from the statistical modelling data set (but retained for the frequencies data set in order to describe the sample) were mother-daughter pairs of which either participant had had an elective caesarean $4 \%(n=14)$. Analysis for statistical modelling included 646 women (323 pairs) who delivered a first birth singleton live infant (Fig. 1).

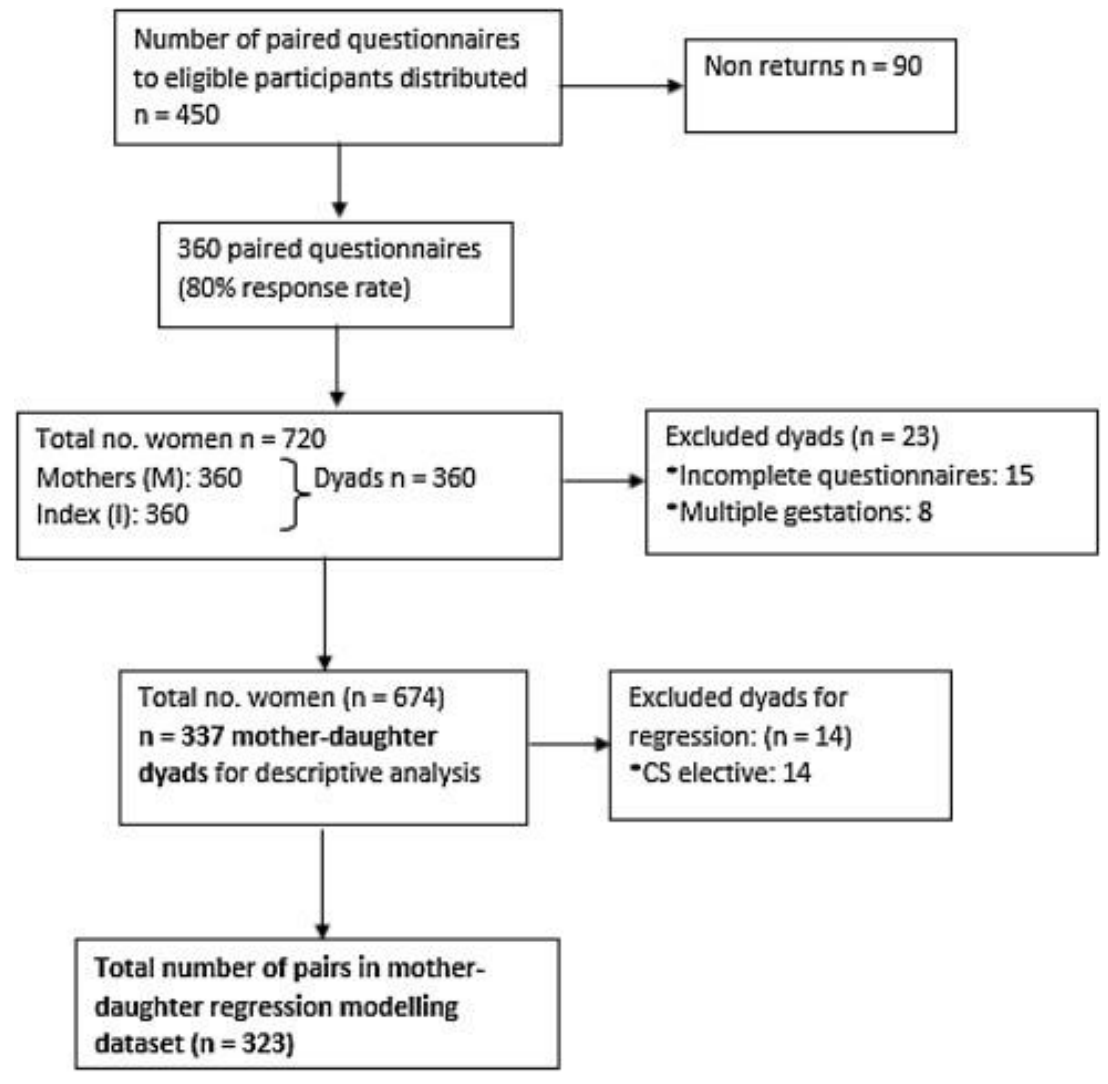

Fig. 1. Flow chart of inclusion in the analysis.

Table 1 provides the demographic and clinical characteristics of the respondents.

Daughters were older than mothers at time of first delivery (mean 30 years ( $S D$ 5.46) vs. 24 years $(S D$ 3.70)). The majority of the sample self-classified as Israeli, married, and with a university education. The most common sign of labour onset overall was 
contractions (daughters $49 \%$; mothers $56 \%$ ) followed by spontaneous or premature rupture of membranes (daughters $23 \%$; mothers $24 \%$ ).

Table 1. Characteristics of the population and clinical outcomes (Daughters in 2015; Mothers in.1967-1998)

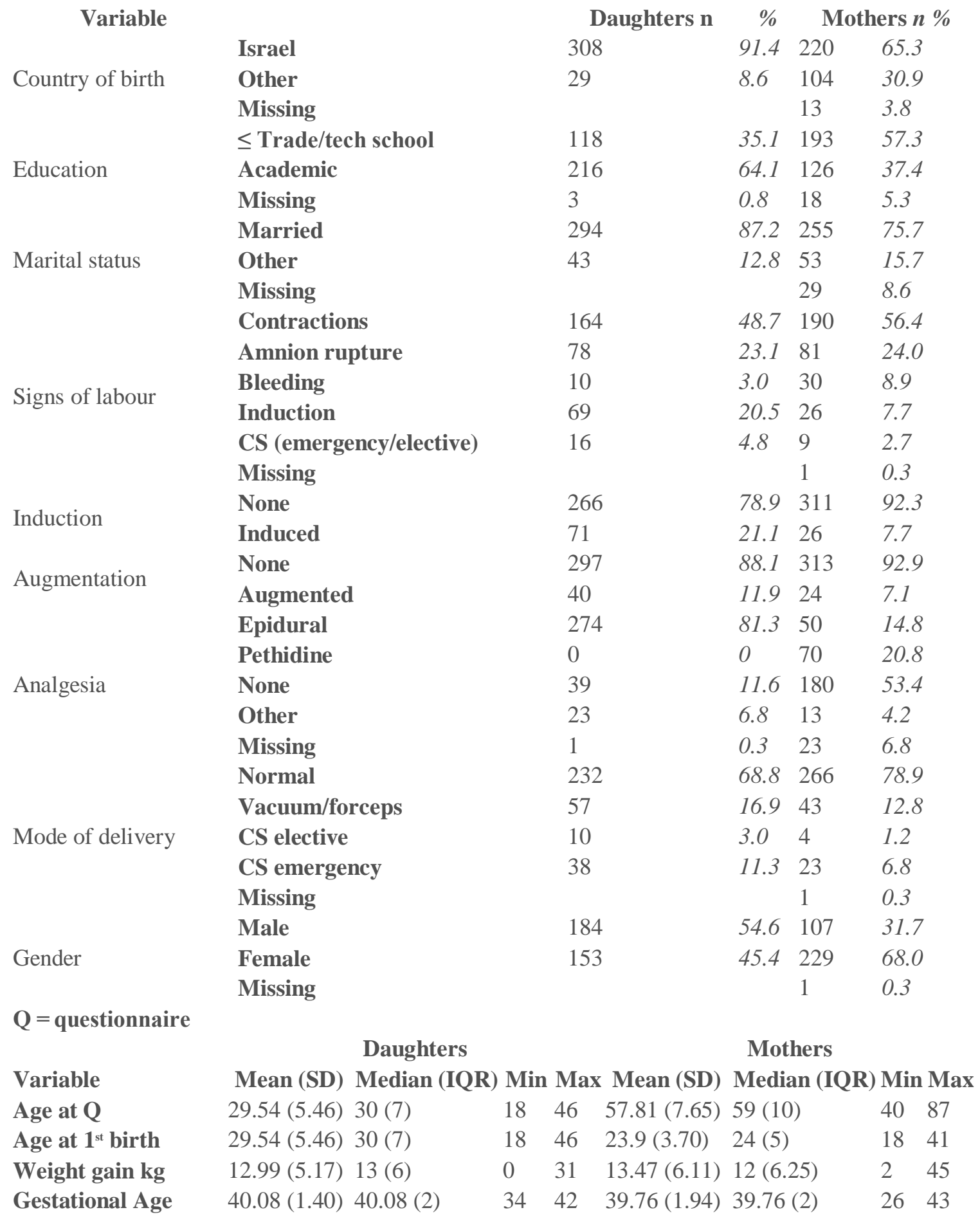


$\mathbf{Q}=$ questionnaire

$\begin{array}{lll}\text { Variable } & \text { Daughters } & \text { Mothers } \\ \text { Mean (SD) } & \text { Median (IQR) Min Max Mean (SD) } & \text { Median (IQR) Min Max }\end{array}$

Foetal body weight g 3273 (443.9) 3273 (557.5) $\quad 187246653176(523.7) 3176(625) \quad 9204700$

Daughters had almost three times the rate of inductions, more than one and a half times the rate of augmentations, over five times the rate of epidural analgesia use, and over one and a half times the rate of emergency caesarean, when compared to their mothers.

Daughters and mothers had similar weight gain, and daughters' babies were born on average one week earlier. Both mothers and daughters had comparable mean and maximum fetal birthweights. Mothers gave birth to over double the number of females than males (females $\mathrm{n}=229,68 \%$ and males $\mathrm{n}=107,32 \%$ ) whereas daughters had a similar gender distribution among their firstborn offspring (females $n=153,45 \%$; males $\mathrm{n}=184,55 \%$ ). This may be explained by the fact that only women who had at least one daughter were recruited to the study (since their recruitment was dependent on that of their parous daughter). Mothers who only had male offspring were not eligible.

Overall, more daughters $(n=169,50 \%)$ laboured for over $10 \mathrm{~h}$ than mothers $(n=123,36$ $\%$ ), (Table 2). Of the total data set, 21 mother-daughter pairs had physiological births (i.e. spontaneous onset and progression of labour resulting in a normal vaginal birth). In this group a similar number of mothers and daughters laboured for less than $10 \mathrm{~h}$ (mothers $\mathrm{n}=18,86 \%$; daughters $\mathrm{n}=17,81 \%$ ), (Table 3 ) which may indicate that for shorter labours there was less clinical pressure to intervene.

Table 2. Matched mother-daughter full data set pairs $(n=337)$ for length of labour in 3 categorical groups.

Variable

Length of Labour in 4 time intervals

Length of Labour in 3 time intervals

\begin{tabular}{|c|c|c|c|c|c|}
\hline \multicolumn{3}{|c|}{ Daughter n \% } & \multicolumn{3}{|c|}{ Mother 1st Birth n \% } \\
\hline 1. $0-2 \mathrm{~h}$ & 6 & 1.2 & 1. $0-2 \mathrm{~h}$ & 36 & 10.6 \\
\hline 2. $>2-6 \mathrm{~h}$ & 42 & 12.5 & 2. $>2-6 h$ & 107 & 31.8 \\
\hline 3. $>6-10 \mathrm{~h}$ & 100 & 29.7 & 3. $>6-10 \mathrm{~h}$ & 63 & 18.7 \\
\hline 4. $>10 \mathrm{~h}$ & 169 & 50.1 & 4. $>10 \mathrm{~h}$ & 123 & 36.5 \\
\hline Missing & 22 & 6.5 & Missing & 8 & 2.4 \\
\hline 1. $0-12 \mathrm{~h}$ & 191 & 56.7 & 1. $0-12 \mathrm{~h}$ & 253 & 75.1 \\
\hline 2. $>12-18 \mathrm{~h}$ & 88 & 26.1 & 2. $>12-18 \mathrm{~h}$ & 42 & 12.4 \\
\hline 3. $>18-24 \mathrm{~h}$ & 36 & 10.7 & 3. $>18-24 \mathrm{~h}$ & 34 & 10.1 \\
\hline Missing & 22 & 6.5 & Missing & 8 & 2.4 \\
\hline
\end{tabular}


Variable

Length of Labour in binary time intervals
Daughter n \%

1. $0-10 \mathrm{~h}$

2. $>10 \mathrm{~h}$

Missing
$14642.81 .0-10 \mathrm{~h}$

16950.7 2.>10h

$22 \quad 6.5$ Missing
20661.1

$123 \quad 36.5$

$8 \quad 2.4$

Table 3. Matched mother-daughter physiological birth pairs $(n=21)$ for length of labour in 3 categorical groups.

\begin{tabular}{|c|c|c|c|c|c|c|}
\hline \multirow[t]{2}{*}{ Variable } & \multicolumn{3}{|c|}{ Daughter n \% } & \multicolumn{3}{|c|}{ Mother 1st Birth n \% } \\
\hline & 1. $0-2 \mathrm{~h}$ & 2 & 9.5 & 1. $0-2 \mathrm{~h}$ & 4 & 19 \\
\hline \multirow{3}{*}{ Length of Labour in 4 time intervals } & 2. $>2-6 \mathrm{~h}$ & 7 & 33.3 & 2. $>2-6 \mathrm{~h}$ & 10 & 47.6 \\
\hline & 3. $>6-10 \mathrm{~h}$ & 8 & 38.1 & 3. $>6-10 \mathrm{~h}$ & 4 & 19 \\
\hline & 4. $>10 \mathrm{~h}$ & 4 & 19.1 & 4. $>10 \mathrm{~h}$ & 3 & 14.4 \\
\hline \multirow{3}{*}{ Length of Labour in 3 time intervals } & 1. $0-12 \mathrm{~h}$ & 18 & 85.7 & $1.0-12 \mathrm{~h}$ & 18 & 85.7 \\
\hline & 2. $>12-18 \mathrm{~h}$ & 2 & 9.5 & 2. $>12-18 \mathrm{~h}$ & 2 & 9.5 \\
\hline & 3. $>18-24 \mathrm{~h}$ & 1 & 4.8 & $3 .>18-24 \mathrm{~h}$ & 1 & 4.8 \\
\hline \multirow{2}{*}{ Length of Labour in binary time intervals } & $1.0-10 \mathrm{~h}$ & 17 & 81 & $1.0-10 \mathrm{~h}$ & 18 & 85.7 \\
\hline & 2. $>10 \mathrm{~h}$ & 4 & 19 & 2. $>10 \mathrm{~h}$ & 3 & 14.3 \\
\hline
\end{tabular}

Daughters' length of labour was shorter for babies born $\leq 38$ weeks than babies born $>38$ weeks (mean $9.41 \mathrm{~h}$ (SD 5.43) vs. (mean $11.62 \mathrm{~h}$ (SD 5.38)) respectively, and shorter for babies born $\leq 3500 \mathrm{~kg}$ than $>3500 \mathrm{~kg}$, (mean $11.15 \mathrm{~h}$ (SD 5.33) vs. (mean $12.15 \mathrm{~h}$ (SD 5.58)) respectively.

Daughters had $10 \%$ fewer natural conceptions and more than one and a half times the rate of abortions than mothers prior to their first deliveries.

Comparative analysis for mother-daughter reproductive outcomes is presented in Table 4. The following seven intrapartum covariates showed statistically significant associations: induction $(p<0.001)$, use of pain relief in labour $(p<0.001)$, gestational age $(p=0.013)$, foetal birthweight $(p=0.001)$, gender $(p<0.001)$, Apgar $(p=0.041)$ and mode of delivery $(p=0.005)$. In the analysis of mother-daughter age at first period, height and weight-gain in pregnancy, no association was seen. 
Table 4. Comparative Analysis of Mother-Daughter Reproductive Outcomes (Excluding Elective Caesarean Section).

Total mother-daughter pairs $\mathbf{n}=\mathbf{3 2 3}$

\begin{tabular}{|c|c|c|c|c|c|c|}
\hline Variable & $\begin{array}{l}\text { Mother- } \\
\text { daughter pairs } \\
\text { (n) }\end{array}$ & Mother & Daughter & Statistical test & $\begin{array}{l}\text { Test } \\
\text { statistic }\end{array}$ & $\begin{array}{l}p \text { - } \\
\text { value }\end{array}$ \\
\hline $\begin{array}{l}\text { Age at 1st period, } \\
\text { median }\end{array}$ & 295 & 13.0 & 13.0 & Wilcoxon & -0.761 & 0.447 \\
\hline $\begin{array}{l}\text { Natural conception } \\
(Y), n(\%)\end{array}$ & 323 & $314(97.2)$ & $278(86.1)$ & McNemar's & 24.5 & $<0.001$ \\
\hline $\begin{array}{l}\text { Abortions/missed (Y), } \\
\mathbf{n}(\%)\end{array}$ & 321 & $33(10.3)$ & $51(15.9)$ & McNemar's & 4.516 & 0.033 \\
\hline Induction (Y), n(\%) & 319 & $26(8.2)$ & $69(21.6)$ & McNemar's & 22.909 & $<0.001$ \\
\hline $\operatorname{Analgesia~(Y),~n(\% )~}$ & 302 & $127(42.1)$ & 267(88.4) & McNemar's & 125.461 & $<0.001$ \\
\hline Gender (Male), n(\%) & 322 & $101(31.4)$ & $176(54.7)$ & McNemar's & 33.188 & $<0.001$ \\
\hline Apgar (Normal), n(\%) & 282 & $277(98.2)$ & $267(94.7)$ & McNemar's & $\mathrm{n} / \mathrm{a}$ & $0.041 \mathrm{a}$ \\
\hline $\begin{array}{l}\text { Foetal birth weight, } \\
\text { mean (SD) }\end{array}$ & 318 & $\begin{array}{l}3172.9 \\
(524.2)\end{array}$ & $\begin{array}{l}3272.6 \\
(438.0)\end{array}$ & Paired T-test & -3.259 & $<0.001$ \\
\hline $\begin{array}{l}\text { Gestational age, } \\
\text { median }\end{array}$ & 316 & 40.0 & 40.0 & Wilcoxon & -2.473 & 0.013 \\
\hline Weight gain, median & 280 & 12.0 & 12.0 & Wilcoxon & -0.416 & 0.678 \\
\hline $\begin{array}{l}\text { Mode of delivery, } \\
\mathrm{n}(\%)\end{array}$ & 322 & & & $\begin{array}{l}\text { Marginal } \\
\text { homogeneity }\end{array}$ & -2.798 & 0.005 \\
\hline Normal & & 257(79.8) & $229(71.1)$ & & & \\
\hline Vacuum/forceps & & $43(13.4)$ & $55(17.1)$ & & & \\
\hline CS emergency & & $22(6.8)$ & $38(11.8)$ & & & \\
\hline Signs of labour, n(\%) & 318 & & & $\begin{array}{l}\text { Marginal } \\
\text { homogeneity }\end{array}$ & -3.316 & $<0.001$ \\
\hline Contractions & & 182(57.2) & 161(50.0) & & & \\
\hline Amnion rupture & & $79(24.9)$ & $78(24.2)$ & & & \\
\hline Bleeding & & $29(9.1)$ & $10(3.1)$ & & & \\
\hline Induction & & $26(8.2)$ & $68(21.1)$ & & & \\
\hline
\end{tabular}


Total mother-daughter pairs $\mathbf{n}=\mathbf{3 2 3}$

Mother-
Vaughter pairs Mother Daughter Statistical test
(n)

$\begin{array}{lll}\text { CS emergency } & 2(0.6) \quad 5(1.6)\end{array}$

$p<0.05$ significance.

Bold values indicate statistical significance was reached.

a

Exact $p$-value calculated with binomial distribution used.

In the logistic regression analysis of mother-daughter $(n=323$ pairs $)$ length of labour $(\leq 10 \mathrm{~h} />10 \mathrm{~h})$ mothers longer labour (>10 h) was associated with almost double the odds for a longer labour in the daughter [OR1.91(95\%CI 1.19,3.05, $p=0.007)$, unadjusted]. In 147 cases, the odds ratio was increased to above three when mothers and daughters were paired for same gender offspring [OR3.23(95\%CI 1.55,6.74, $p=0.002)$ ] (Table 5).

Table 5. Univariate logistic regression (dependent variable length of labour binary daughter, $\leq 10 \mathrm{~h} />10 \mathrm{~h}$ ).

Independent variable

Length of labour Binary M (ref.: short labour)

Age 1st Period D

Age 1st Period M

Education D (ref.: academic)

Primary and High school

Full high school

Higher education

Education M (ref.: academic)

Primary and High school

Full high school

Higher education

Height D

Height M $p \quad$ OR $95 \% \mathrm{CI}$

$\begin{array}{llll}0.007 & 1.91 & 1.193 & 3.05\end{array}$

$\begin{array}{llll}0.709 & 0.97 & 0.83 & 1.14\end{array}$

$\begin{array}{llll}0.015 & 0.82 & 0.70 & 0.96\end{array}$

0.214

0.410

$\begin{array}{lll}0.47 & 0.08 \quad 2.86\end{array}$

$\begin{array}{llll}0.463 & 0.78 & 0.39 & 1.53\end{array}$

$\begin{array}{llll}0.047 & 0.56 & 0.32 & 0.99\end{array}$

0.292

$\begin{array}{llll}0.919 & 1.05 & 0.41 & 2.70\end{array}$

$\begin{array}{llll}0.161 & 0.67 & 0.39 & 1.17\end{array}$

$\begin{array}{llll}0.106 & 0.60 & 0.32 & 1.12\end{array}$

$\begin{array}{llll}0.203 & 0.10 & 0.00 & 3.53\end{array}$

$\begin{array}{llll}0.258 & 0.13 & 0.00 & 4.44\end{array}$ 
Independent variable

Marital Status D (ref.: married)

Single

Divorced

Other

*Marital Status M (ref.: married)

Divorced

Other

Weight Gain D

Weight Gain M

Age D

Age at 1st birth M

Induction D (bin)(ref: no)

Onset of labour D (ref.: contractions)

Fluid rupture

Bleeding

Induction

Onset of labour M (ref.: contractions)

Fluid rupture

Bleeding

Induction/Elec CS

Anaesthesia D (ref.: epidural)

Spinal

None

Anaesthesia D (bin)(ref.: yes)

Anaesthesia M (ref.: none)

Epidural

Pethidine

\begin{tabular}{|c|c|c|c|}
\hline \multirow{2}{*}{$\begin{array}{l}\boldsymbol{p} \\
0.282\end{array}$} & \multirow[t]{2}{*}{ OR } & \multicolumn{2}{|c|}{$95 \%$ CI } \\
\hline & & & \\
\hline 0.105 & 3.96 & 0.84 & 18.64 \\
\hline 0.646 & 1.76 & 0.16 & 19.62 \\
\hline 0.802 & 0.88 & 0.32 & 2.41 \\
\hline \multicolumn{4}{|l|}{0.079} \\
\hline 0.541 & 0.79 & 0.38 & 1.66 \\
\hline 0.748 & 1.19 & 0.41 & 3.45 \\
\hline$<0.001$ & 1.11 & 1.05 & 1.16 \\
\hline 0.593 & 1.01 & 0.97 & 1.05 \\
\hline$<0.001$ & 1.09 & 1.04 & 1.14 \\
\hline 0.240 & 1.04 & 0.98 & 1.10 \\
\hline 0.386 & 1.27 & 0.74 & 2.19 \\
\hline \multicolumn{4}{|l|}{0.631} \\
\hline 0.862 & 1.05 & 0.60 & 1.83 \\
\hline 0.435 & 0.60 & 0.16 & 2.19 \\
\hline 0.344 & 1.32 & 0.74 & 2.36 \\
\hline \multicolumn{4}{|l|}{0.885} \\
\hline 0.860 & 0.95 & 0.56 & 1.63 \\
\hline 0.462 & 0.74 & 0.33 & 1.66 \\
\hline 0.670 & 0.85 & 0.39 & 1.82 \\
\hline \multicolumn{4}{|l|}{$<0.001$} \\
\hline 0.403 & 0.46 & 0.08 & 2.82 \\
\hline$<0.001$ & 0.22 & 0.10 & 0.47 \\
\hline$<0.001$ & 0.22 & 0.10 & 0.48 \\
\hline \multicolumn{4}{|l|}{0.912} \\
\hline 0.954 & 0.98 & 0.52 & 1.86 \\
\hline 0.605 & 1.17 & 0.65 & 2.11 \\
\hline
\end{tabular}




\begin{tabular}{|c|c|c|c|c|}
\hline Independent variable & $p$ & OR & $95 \%$ & \\
\hline Nitrous oxide & 0.411 & 2.60 & 0.27 & 25.54 \\
\hline Spinal & 0.499 & 0.43 & 0.04 & 4.88 \\
\hline General & 0.775 & 1.30 & 0.21 & 7.99 \\
\hline Augment D (bin) (ref.: none) & 0.040 & 2.18 & 1.04 & 4.59 \\
\hline Augment M (bin) (ref.: none) & 0.526 & 0.76 & 0.32 & 1.80 \\
\hline Foetus body weight $\mathrm{kg} \mathrm{D}$ & 0.137 & 1.00 & 1.00 & 1.00 \\
\hline Foetus body weight $\mathrm{kg} \mathrm{M}$ & 0.079 & 1.00 & 1.00 & 1.00 \\
\hline Gestational Age D & 0.053 & 1.18 & 1.00 & 1.40 \\
\hline Gestational Age M & 0.086 & 1.12 & 0.98 & 1.27 \\
\hline Gender D (ref.: male) & 0.762 & 1.07 & 0.68 & 1.68 \\
\hline Gender M (ref.: male) & 0.144 & 1.44 & 0.88 & 2.35 \\
\hline Mode of delivery D (ref.: normal) & 0.060 & & & \\
\hline Vacuum/forceps & 0.131 & 1.59 & 0.87 & 2.91 \\
\hline CS Emergency & 0.046 & 2.53 & 1.02 & 6.28 \\
\hline Mode of delivery M(ref.: normal) & 0.250 & & & \\
\hline Vacuum/forceps & 0.697 & 0.88 & 0.46 & 1.69 \\
\hline CS Emergency & 0.116 & 2.20 & 0.82 & 5.84 \\
\hline Length of labour Binary M with M-D gender filter & 0.002 & 3.23 & 1.55 & 6.74 \\
\hline $\mathrm{D}=$ daughter, $\mathrm{M}=$ mother. & & & & \\
\hline$($ bin $)=$ binary variable & & & & \\
\hline $\mathrm{p}<0.05$ sig. & & & & \\
\hline Bold values indicate statistical significance was reached. & & & & \\
\hline
\end{tabular}

In the analysis of other factors, such as marital status, height, and age at first period, and daughters' onset of labour and induction, no association with length of labour was seen. Univariate logistic regression analysis (Table 5) showed daughters' increasing age and weight-gain appeared to increase the likelihood of longer labour durations [OR1.09(95 
$\%$ CI 1.04,1.14,p<0.001)] and [OR1.11(95\%CI 1.05,1.16,p<0.001)] respectively. A suggestion of possible increased odds of longer labour with an increase in daughters gestational age [OR1.18(95 \%CI 1.00,1.40,p=0.053)] was also observed. Shorter labour in daughters was highly significantly associated with non-pharmacological pain relief in labour [OR 0.22(95\%CI 0.10,0.47,p<0.001)] reference category epidural use $(p<0.001)$. Overall association between daughters' mode of delivery and length of labour was not statistically significant $(p=0.060)$, however, women having an emergency caesarean had 2.5 times higher odds of having a long labour compared to women having a normal delivery (OR2.53, $p=0.046)$.

Variables that were found to be statistically significant in the univariate analysis at level $p<0.1$ were explored in a multivariable logistic regression model. A predictive model for daughters' length of labour included mothers' length of labour $(\leq 10 \mathrm{~h} />10 \mathrm{~h})$, daughters' age, daughters' weight-gain in pregnancy, and daughters' use of anesthesia.

The adjusted odds ratio for daughters having a long labour if their mothers also had a long labour was [OR1.88(95\%CI 1.12,3.17, $p=0.017)]$. All variables in the model with significant p-values increased the odds for long length of labour in daughters except nonuse of anaesthesia. Women who did not have any analgesia during labour had considerably lower chances of long labour compared to those women who had epidural anaesthesia [OR0.27(95\%CI 0.12,0.60),p $<0.001]$. Results for multiple logistic regression are presented in Table 6.

Table 6. Multivariable logistic regression for daughters' length of labour.

(Constant)

Length of labour M (<10hrs/>10hrs)

Age (D)

Analgesia (D) (ref. Epidural)

Analgesia (D) (Spinal)

Analgesia (D) (None)

Weight gain (D)

$\mathrm{M}=$ Mother.

\begin{tabular}{rlrr}
\multicolumn{1}{c}{$\boldsymbol{B}$} & \multicolumn{1}{c}{$\boldsymbol{p}$} & OR & $\mathbf{9 5} \% \mathbf{C I}$ \\
-4.58 & $<\mathbf{0 . 0 0 1}$ & & \\
0.63 & $\mathbf{0 . 0 1 7}$ & 1.88 & $1.12,3.17$ \\
0.08 & $\mathbf{0 . 0 0 5}$ & 1.08 & $1.02,1.14$ \\
& $\mathbf{0 . 0 0 3}$ & & \\
-1.35 & 0.16 & 0.26 & $0.04,1.72$ \\
-1.32 & $<\mathbf{0 . 0 0 1}$ & 0.27 & $0.12,0.60$ \\
0.10 & $<\mathbf{0 . 0 0 1}$ & 1.10 & $1.04,1.16$
\end{tabular}

$\mathrm{D}=$ Daughter. 
The multivariable logistic regression model showed a very good fit (Hosmer and Lemeshow $p=0.943$ ) and allowed for correct classification of long length of labour in 66 $\%$ of cases (accuracy) with reasonable sensitivity (74\%) and specificity (56\%). $66 \%$ of daughters who were predicted by the model to have a long labour did in fact do so (positive predictive value), and $64 \%$ of daughters who were identified by the model as not having high risk of long labour actually had a labour of less than $10 \mathrm{~h}$ (negative predictive value).

The predictive properties of the model using a ROC analysis (Fig. 2) yielded an Area Under the Curve result of 0.72 (95\% CI 0.60, 0.77, $p<0.001)$, which is considered a fair and acceptable level of discrimination [20].

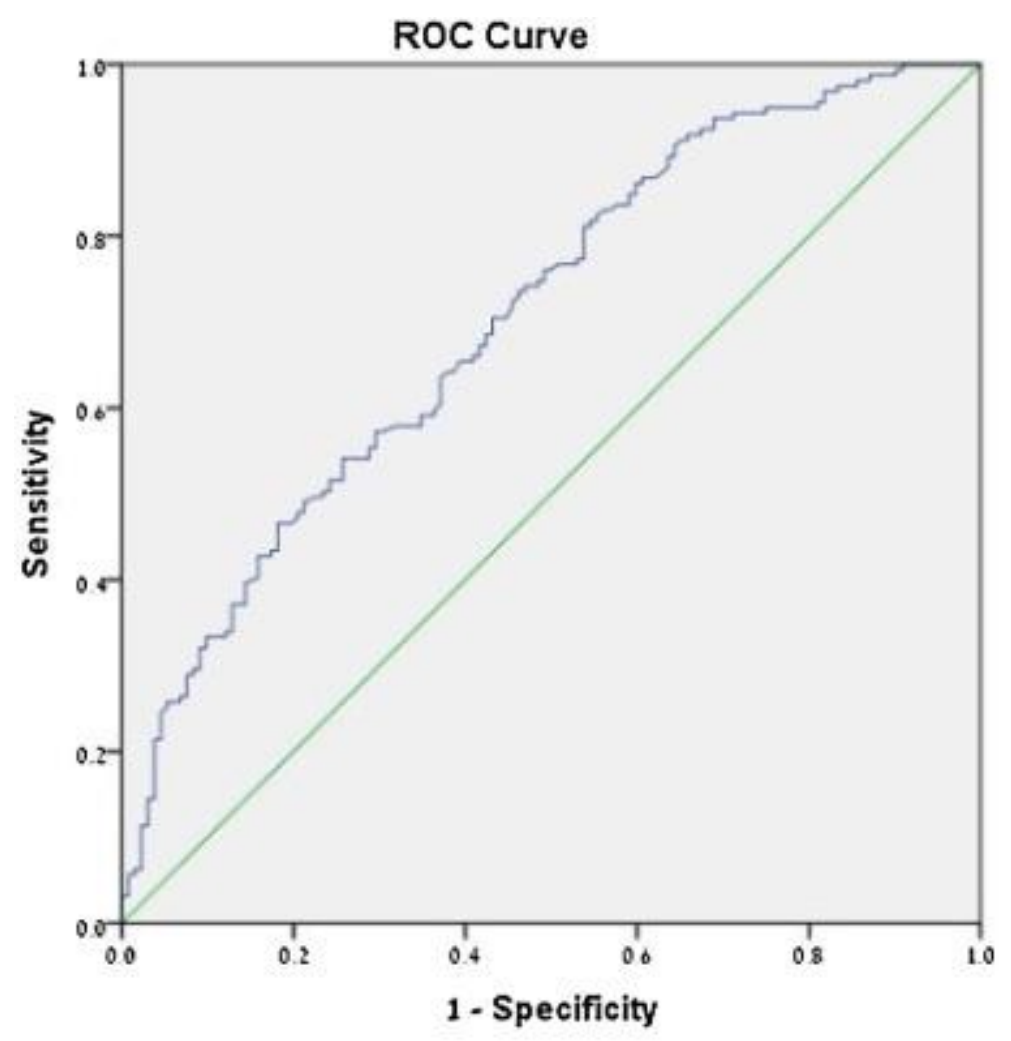

Diagonal segments are produced by ties

Fig. 2. Receiver Operating Characteristic Curve - Graphical Representation of the Prediction Capacity of the Model. 


\section{Comment}

Intervention rates were much higher in the daughters' cohort. Greater mean maternal age in the daughters may partially account for the higher labour and delivery intervention rates [21] and caesarean section rates [22]. However, this is unlikely to fully explain the large differences between two generations of childbearing women.

Analysis of data from 323 mother-daughter pairs showed that if a mother had a long labour ( $>10 \mathrm{~h}$ ), the corresponding odds of a long labour was almost two-fold for the daughter. The odds ratio was increased to above three when mothers and daughters were paired for same gender offspring.

Mothers' labour length, daughters' age, daughters' weight-gain in pregnancy, and daughters' use of epidural anesthesia significantly influenced daughters' labour length. It was observed that daughters with larger fetal birthweight and longer gestational age tended to have longer labour durations which may better inform expected duration of labour for certain subgroups of this population.

Age, weight-gain in pregnancy, and use of anesthesia are known to have influences on length of labour [23], [24], [25]. Induction, fetal birthweight and gestational age did not seem to have the predicted impact on longer or shorter labours. Other stronger associations may have affected these variables. Medical induction of labour, and augmentation with oxytocin, produces a greater analgesic requirement than spontaneous labour [26]. Induction of labour for suspected fetal macrosomia and elective caesarean section for a predicted birth weight of $>4000 \mathrm{~g}$ may have reduced the number of high birthweight babies in the daughters' cohort. Length of gestational age may have been reduced by policies of routine labour induction for pregnancies considered 'post-term'. Length of labour may have been reduced by the use of labour augmentation, which occurred in $12 \%$ of the daughters compared to $7 \%$ of the mothers.

Strengths of the study included a high response rate, a substantial matched cohort, and inclusion of changes in clinical practice over time in the statistical modelling. Limitations included uncertainty of labour length measurements given that there is no defined criteria 
to indicate labour onset, the possibility that interventions may have affected labour length, and the potentially limited generalizability of findings. Self-report of labour duration may be a further limitation, although previous research has demonstrated that women accurately recall labour and birth events many years after birth [27].

Strong positive mother-daughter associations were found in lengths of labour during first births that persisted after adjusting for the increased number of interventions in the modern cohort. Maternal labour patterns may be used as an additional heuristic to guide practice, alongside evidence, signs and symptoms exhibited by individual women.

Further research should also consider the influence that health behaviours and lifestyle factors have on length of labour, such as physical exercise habits, smoking, stress and depression levels. In addition, longitudinal studies which explore the possible effect on a third generation are warranted.

\section{Author contributions}

Each author made substantial contributions to conception and design of the study, the assessment of data and development of the manuscript. Responsible for acquisition of data $(\mathrm{ME})$, analysis and interpretation of data (ME, SD, ST), preparation of results tables (ME, ST), interpretation of results (ME, SD, ST), intellectual input and comments on the manuscript (ME, AM, SD, ST, VHM), writing of first and final draft of the manuscript (AM, ME, SD, ST, VHM). All authors contributed to drafting and revising the manuscript. All authors read and approved the final version.

\section{Funding}

ME is a doctoral graduand (2019) UCLan, UK. The research was self-funded.

\section{Ethics approval and consent to participate}

Use of the questionnaire and project approval was granted by the Helsinki ethics committees of the two hospitals (protocol nos. 0039-14-TLV 12.06.14, and Ver:1-72.14 30.07.14), and the University of Central Lancashire Research Ethics Committee, School 
of Health, UK. (approval number ref: STEMH 255, 09.09.2014). All participants signed an informed consent form.

\section{Availability of data and material}

The data file is available upon request to the corresponding author after receiving approval from the University of Central Lancashire STEMH ethics committee subject to data sharing agreement.

\section{Declaration of Competing Interest}

The authors report no conflict of interests.

\section{Acknowledgement}

We thank Dr. Benny Chayen from MH for his assistance with ethics approval for this research.

\section{References}

[1] T. Olufemi, O.T. Oladapo, J.P. Souza, B. Fawole, K. Mugerwa, G. Perdona, et al. Progression of the first stage of spontaneous labour: a prospective cohort study in two sub-Saharan African countries

PLoS Med (2018), 10.1371/journal.pmed.1002492

Google Scholar

[2] WHO Recommendation on duration of the first stage of labour; recommendation on definition and duration of the second stage of labour (Abalos et al. 2018)

Google Scholar

[3] E. Abalos, O.T. Oladapo, M. Chamillard, V. Díaz, J. Pasquale, M. Bonet, et al. Duration of spontaneous labour in' low-risk' women with' normal' perinatal outcomes: a systematic review Eur J Obstet Gynecol Reprod Biol, 223 (2018), pp. 123-132 
ArticleDownload PDFView Record in ScopusGoogle Scholar

[4] G.H.A. Visser, D. Ayres-de-Campos, E.R. Barnea, L. de Bernis, G.C. Di Renzo, M.F. Escobar Vidarte, et al. FIGO position paper: how to stop the caesarean section epidemic

Lancet, 392 (10155) (2018), pp. 1286-1287

ArticleDownload PDFView Record in ScopusGoogle Scholar

[5] J.L. Neal, N.K. Lowe, K. Ahijevych, T.E. Patrick, L.A. Cabbage, E.J. Corwin. Active labor duration and dilation rates among low-risk, nulliparous women with spontaneous labor onset: a systematic review

J Midwifery Womens Health, 55 (2010), pp. 308-318, 10.1016/j.jmwh.2009.08.004

ArticleDownload PDFCrossRefView Record in ScopusGoogle Scholar

[6] J.L. Bailit, L. Dierker, M.H. Blanchard, B.M. Mercer. Outcomes of women presenting in active versus latent phase of spontaneous labor

Obstet Gynecol, 105 (1) (2005), pp. 77-79

View Record in ScopusGoogle Scholar

[7] P. Rahnama, S. Ziaei, S. Faghihzadeh. Impact of early admission in labor on method of delivery

Int J Gynaecol Obstet, 92 (3) (2006), pp. 217-220

ArticleDownload PDFCrossRefView Record in ScopusGoogle Scholar

[8] R. Mikolajczyk, J. Zhang, J. Grewal, L. Chan, A. Petersen, M.M. Gross. Early versus late admission to labor affects labor progression and risk of cesarean section in nulliparous women Front Med (Lausanne), 3 (2016), p. 26

Google Scholar

[9] P. Magnus, L.S. Bakketeig, R. Skjaerven. Correlations of birth weight and gestational age across generations

Ann Hum Biol, 20 (1993), pp. 231-238

CrossRefView Record in ScopusGoogle Scholar

[10] C. Kuzawa, D. Eisenberg. Intergenerational predictors of birth weight in the Philippines: correlations with mother's and father's birth weight and test of maternal constraint PLoS One, 7 (2012), Article e40905 
CrossRefGoogle Scholar

[11] T.I. Nordtveit, K.K. Melve, R. Skjaerven. Intergenerational birth weight associations by mother's birth order - the mechanisms behind the paradox: a population-based cohort study Early Hum Dev, 85 (2009), pp. 577-581

ArticleDownload PDFView Record in ScopusGoogle Scholar

[12] I. Mogren, H. Stenlund, U. Hogberg. Recurrence of prolonged pregnancy

Int J Epidemiol, 28 (1999), pp. 253-257

View Record in ScopusGoogle Scholar

[13] N.-H. Morken, K.K. Melve, R. Skjaerven. Recurrence of prolonged and post-term gestational age across generations: maternal and paternal contribution

Int J Gynaecol Obstet, 118 (13) (2011), pp. 1630-1635

CrossRefView Record in ScopusGoogle Scholar

[14] M.L. Berg-Lekås, U. Hogberg, A. Winkvist. Familial occurrence of dystocia

Am J Obstet Gynecol, 179 (1998), pp. 117-121

ArticleDownload PDFView Record in ScopusGoogle Scholar

[15] M. Algovik, E. Nilsson, S. Cnattingius, P. Lichtenstein, A. Nordenskjold, M. Westgren. Genetic influence on dystocia

Acta Obstet Gynecol Scand, 83 (2004), pp. 832-837

View Record in ScopusGoogle Scholar

[16] M.W. Varner, A.M. Fraser, C.Y. Hunter, P.S. Corneli, R.H. Ward. The intergenerational predisposition to operative delivery

Obstet Gynecol, 87 (1996), pp. 905-911

ArticleDownload PDFCrossRefView Record in ScopusGoogle Scholar

[17] M.C. Tollånes, S. Rasmussen, L.M. Irgens. Caesarean section among relatives

Int J Epidemiol, 37 (2008), pp. 1341-1348 
CrossRefView Record in ScopusGoogle Scholar

[18] P. Peduzzi, J. Concato, E. Kemper, T.R. Holford, A.R. Feinstein. A simulation study of the number of events per variable in logistic regression analysis

J Clin Epidemiol, 49 (1996), pp. 1373-1379

ArticleDownload PDFView Record in ScopusGoogle Scholar

[19] D.W. Hosmer Jr, S. Lemeshow, R.X. Sturdivant. Model-building strategies and methods for logistic regression

Applied logistic regression (third edition) (2000), pp. 89-151

View Record in ScopusGoogle Scholar

[20] D.W. Hosmer, S. Lemeshow. Applied logistic regression

CBSU Library (second edition), Wiley, New York (2000)

Google Scholar

[21] L. Herstad, K. Klungsøyr, R. Skjærven, T. Tanbo, L. Forsén, T. Åbyholm, et al. Elective cesarean section or not? Maternal age and risk of adverse outcomes at term: a population-based registry study of low-risk primiparous women

BMC Pregnancy Childbirth (2016), 10.1186/s12884-016-1028-3

BMC series - open, inclusive and trusted 201616:230

Google Scholar

[22] G. Janoudi, S. Kelly, A. Tasseen, H. Hamam, F. Moretti, M. Walker. Factors associated with increased rates of caesarean section in women of advanced maternal age

JOGC; Journal of Obstetrics and Gynaecology Canada (2015), 10.1016/S1701-2163(15)30228-0

Google Scholar

[23] M.B. Greenberg, Y.W. Cheng, M. Sullivan, M.E. Norton, L.M. Hopkins, A.B. Caughey. Does length of labor vary by maternal age?

Am J Obstet Gynecol, 197 (428) (2007), pp. e1-e428 
View Record in ScopusGoogle Scholar

[24] W.F. Mousa, R. Al-Metwalli, M. Mostafa. Epidural analgesia during labor vs no analgesia: a comparative study

Saudi J Anaesth, 6 (January-March (1)) (2012), pp. 36-40

CrossRefView Record in ScopusGoogle Scholar

[25] S. Yazdani, Y. Yosofniyapasha, B.H. Nasab, M. Haghshenas Mojaveri, Z. Bouzari. Effect of maternal body mass index on pregnancy outcome and newborn weight

BMC Res Notes, 5 (2012), p. 34, 10.1186/1756-0500-5-34

Published online 2012 Jan 17

CrossRefGoogle Scholar

[26] G. Capogna. Minimum analgesic dose of epidural and sufentanil for first-stage labor analgesia: a comparison between spontaneous and prostaglandin-induced labors in nulliparous women

Anesthesiology, 94 (5) (2001), pp. 740-744

View Record in ScopusGoogle Scholar

[27] L.M. Hopkins, A.B. Caughey, J.S. Brown, et al. Concordance of chart abstraction and patient recall of intrapartum variables up to 53 years later

Am J Obstet Gynecol, 196 (2007), p. 3

View Record in ScopusGoogle Scholar 